enduring emotional attachment and, thus, an abnormal tendency for the will to be influenced by various inner and outer stimuli; they 'blow hot and cold'. They range from excitable to the apathetic."

The term is also found untranslated in the French edition of the ICD-10: "F60.8 . . inclure: personnalité de type 'haltlos' . . .. But it is certainly not in widespread use in French psychiatry, and I doubt whether it is much used in Germany either.

Incidentally, 'haltlose' is just the feminine form of 'haltlos', the German word for 'personality' (Persönnlichkeit) being feminine.

BLEULER, M. (1983) Eugen Bleuler: Lehrbuch der Psychiatrie (15th edn), p. 574. Berlin: Springer-Verlag.

Peters, U. H. (1984) Wöterbuch der Psychiatrie und medizinischen Psychologie (3rd edn), p. 445. Munich: Urban and Schwarzenberg.

WORLD HEALTH ORGanIzaTION (1992) The ICD-10 Classification of Mental and Behavioural Disorders: Clinical Descriptions and Diagnostic Guidelines. Geneva: WHO.

PAUl Balley, FORENAP, Secteur 8, Centre Hospitalier, F-68250 Rouffach

\section{Financial implications of Calman changes in psychiatry}

Sir: I have sympathy with Zubin Bhagwager's (Psychiatric Bulletin. December 1997, 21, 784785) comments about the financial implications of Calman implementation in postgraduate training, having previously expressed concerned about the way the College implemented the changes (Double, 1994). I understand the College having taken the approach of minimal change and I do think that it can be proud of its structure of general professional and specialist training. However, I find it difficult to see the motivation for change in the present structure and I do think it needs to move on to meet the needs of current mental health training and services.

The balance between general professional and specialist training is wrong, as I previously argued. Clinical responsibility should be delegated to trainees on the basis of experience and still too much is expected of senior house officers, while their specialist and senior registrar colleagues are able to take advantage of their 'supernumerary' status. As training develops in other specialities, I think this contrast is likely to become more transparent and adversely affect recruitment to psychiatry.

Moreover, general professional training is still too hospital based. The College with some foresight several years ago produced a report by David Julier on The Implications for Training of a Shift to a Community Orientated Service', but this report seems to have had little impact and anyway was never radical enough about the introduction of community psychiatry. One of the factors for the present malaise and scandal of mental health services may be the attitudes and practices of consultant psychiatrists. It is difficult to change this situation without introducing proper community psychiatric training at the beginning of structured training, which may require more of an overhaul of training structures than the College seems prepared to contemplate.

Double, D. B. (1994) The Calman Report on specialist training. Psychiatric Bulletin, 18, 699.

D. B. Double, Consultant Psychiatrist, Norfolk Mental Health Care NHS Trust, Hellesdon Hospital, Drayton High Raod, Norwich NR6 5BE

\section{Psychiatry and the WWW: some implications}

Sir: Senior et als article (Psychiatric Bulletin, December 1997, 21, 775-778) clearly highlights the increasing role the World Wide Web will play in future psychiatric practice and research. One interesting dimension is its use by psychiatric patients. Many of our patients with Chronic Fatigue Syndrome (CFS) have used the information disseminated on the CFS web-site and benefited from it. Concern has been expressed, though, about the range and quality of the information that is available on-line and about the effect on patients of accessing such data sites. The Internet has an important role to play in every aspect of patient care including interviewing patients but caution must be exercised in the extent to which we 'mechanise' such a purely human interaction as a psychiatric interview.

We recurrently assessed a female patient who had taken a potentially serious overdose of simple analgesic and antidepressant tablets with alcohol and left a message on the Internet, meant to be a 'suicide note'. This message was picked up by a stranger in the United States, who fortunately alerted the British police. The patient was alsone at home but the police broke into her house about five hours after the overdose attempt and brought her to the accident and emergency department. Her life was saved because of the 'electronic suicide note' and the presence of mind of the person who picked it up and alerted the police across the Atlantic.

This incident raises some interesting points. First, if this method increases in popularity, this could be very risky as such messages may not be picked up, taken seriously or acted upon. Second, it gives a clue to the high intentionality 